\title{
Nationwide Library Consortia Life Cycle
}

\author{
PNINASHACHAF \\ School of Information and Library Science, University of North Carolina at Chapel Hill, \\ Chapel Hill, NC, USA
}

\begin{abstract}
Library consortia development processes were examined from an ecological approach, combining historical perspective, dynamic developmental approach, and social structure, stressing the issues of permeable boundaries in library consortia and the manifestation of inter-organization relationships. A comparative analysis of several nationwide consortia (from Australia, Brazil, China, Israel, Italy, Micronesia, Spain and the U.K.) using six criteria enables delineation of a developmental pattern. Additional support for
\end{abstract}

the model is based on a study of U.S. statewide consortia conducted by Potter in 1997. A four-stage life cycle sequence is outlined: embryonic, early development, development, and maturation. In addition, the ecological approach stresses founding and disbanding processes, suggesting disbanding as a fifth stage. The contribution of this paper to developmental theories at other levels of analysis (individual, group, organization) is in proposal of an inter-organizational life cycle model.

\section{Introduction}

Electronic publishing and telecommunication have enabled library consortia to expand both in number and functions over the last decade. Library consortium development is rooted in the history of library cooperative efforts and is now also driven by the need to provide remote users with licensed access to electronic resources. This paper will explore the life cycle and developmental stages of nationwide library consortia through a comparative analysis of eight nationwide consortia.

For the purpose of conducting a comparative analysis of nationwide consortia, the term consortium should be clearly defined first. Then, common characteristics of the nationwide library purchasing consortia will be outlined.

A consortium is "an agreement, combination, or group (as of companies) formed to undertake an enterprise beyond the resources of any one member" (Merriam Webster Dictionary), and it "usually involves horizontal collaboration among direct competitors" (Aldrich, Bolton, and Sasaki 1998).
Library consortia vary in their type, goals, structure, membership, and funding (Woodsworth 1991). A consortium may be a formal or informal agreement between libraries based on a common principle. For example, a consortium may be based on library type - academic, medical, or public. A regional consortium may be based on a geographical principle. A statewide or nationwide consortium may incorporate all its libraries, government-funded and those in private institutions. This paper will focus examination on nationwide consortia that involve libraries on a national basis.

Although library consortia form to achieve shared goals, the main goals of cooperation vary. One of the most common goals is resource sharing through union catalogue and interlibrary loan agreements. Electronic resources licensing is another goal, aiming to reduce costs per unit through formation of purchasing consortia. These (nationwide) purchasing consortia will be the focus of this analysis.

This study aims to describe the development process of library consortia by combining an historical perspective with current development

Pnina Shachaf is Doctoral Student. School of Information and Library Science, CB\# 3360, 100 Manning Hall, University of North Carolina at Chapel Hill, Chapel Hill, NC 27599-3360, U.S.A. Tel: 919-966-3589. E-mail: fichp@ils.unc.edu . 
trends, applying a comparative methodology. Existing literature on library consortia has been from either a practitioner or an historical perspective. The practitioner perspective emphasizes the benefits of library cooperation and describes best practices. Library cooperation is therefore a means towards greater access to resources, beyond the ability of any single library. The second approach to library consortia is the historical perspective on development (Woodsworth 1991, Kopp 1998, Alexander 2000). Most of the articles apply anecdotal, descriptive, or case studies approach, with only one article offering a comparative analysis of library consortia (Potter 1997, Adler 1999, Costello 1999, Friend 1999, Cutright 2000, Dai, Chen, and Zhang 2000, Barrionuevo 2000, Krzyzanowski and Taruhn 2000, Giordano 2000). However, various dimensions of library consortia are still unexplored. One such unexplored aspect is the life cycle of consortia. Following the assumption of universal stages of development for groups and organizations, developmental stages for the inter-organization life cycle will be delineated in an ecological approach.

The following section will describe the underlying ecological approach and the theoretical assumptions for this study. Later the methodology and sample will be described and explained. The third section will present the findings from the comparative analysis, and the framework for interorganizational life cycle will be described. Finally, the discussion will emphasize the contribution of this study in the context of the relevant studies.

\section{Ecological approach to consortia}

The ecological approach to library consortia development is influenced by several ecological theories, such as ecological psychology at the individual level (Barker 1968, Bronfenbrenner 1979, Wicker 1979) and at the group level (Sundstrom, DeMuese and Futrell 1990). In this approach, a consortium is perceived as an organism, and these basic assumptions are made (Wicker 1979):

1. A consortium organism cannot be considered to exist or act in isolation. Every consortium is linked with other organisms in a complex network of relationships.

2. A consortium organism is affected by internal forces, such as leadership, as well as by external forces of other organisms, such as competitors and customers.
3. A consortium adapts to achieve harmonious working relationships in its environment, distinguishing between what is appropriate to its needs and what is not.

A life cycle approach to consortium development from an ecological perspective places the consortium's formation and disbandment processes in the context of environment. Affected by the environment, these processes cannot be understood outside that unique context. Each consortium is affected by several levels of the environment at different stages of its development, from its founding to its disbanding. The general environment (legal, political, social and cultural) and the task environment (libraries, consortia, publishers, vendors, and patrons) influence the consortium's formation, development and disbandment.

Further, consortia face the need to manage boundaries as an ongoing process, especially at specific developmental stages. Successful boundaries management is achieved through a balance of differentiation and integration. On one hand, a consortium must differentiate itself from its environment, as a unique organization, with a unique definition of goals, funds, and members. Unsuccessful differentiation threatens the consortium's viability. On the other hand, the consortium must aim for integration with its environment, in order to coalesce with publishers, vendors, and libraries. Too little integration will result in isolation, reducing consortia effectiveness and perhaps leading to eventual dissolution.

Additional assumptions can be made at this point. First, consortia have a life cycle, which is developmental. This life cycle consists of several stages, common to all consortia, despite social, political, cultural and technological differences. Second, the consortia development occurs in the context of specific environments, each bearing constraints and opportunities for consortia construction.

\section{Methodology}

The methodological approach of this study that aims to generate theory is comparative analysis (Glaser and Strauss 1967). The following paragraphs will first outline the rational for comparative analysis in the context of this study. Then, the sampling method for the comparative analysis 
will be presented. Finally, the selection of Potter's criteria (1997) for this comparison will be explained.

The purpose of comparative analysis methodology in this study is to generate a theory through the process of constant comparative analysis that consists of four stages: "(1) comparing incidents applicable to each category, (2) integrating categories and their properties, (3) delimiting the theory, and (4) writing the theory" (Glaser and Strauss 1967, 105). The theory is generated through a systematic comparison of eight library consortia case studies, using six comparison criteria.

The sampling process was based on several considerations. First, the consortia were selected on their similarities; a. type - their type as nationwide consortia; and b. goals - their goals of purchasing and licensing electronic databases. Second, the consortia were selected on a rationale provided by Glaser and Strauss (1967) for theoretical sampling. This theoretical sampling is the process of collecting data for comparative analysis, and is especially intended to facilitate the generation of theory. The cases are selected for comparison on the basis of their theoretical relevance providing relevant data for the emerging theory. For that reason, the first sample of nationwide purchasing consortia did not include Brazil, Italy and Micronesia. However, later, as the theory and categories developed, and in order to provide more understanding of the first and second stages of the model these cases were included. Following that rationale, the cases of the US statewide consortia were supportive of the last stage in the framework.

Information Technology and Libraries has published several case studies describing many nationwide consortia that emerged during the 1990s around the world. Eight of these cases will be examined in this comparative analysis, adopting six criteria that Potter (1997) used to compare U.S. statewide academic library consortia.

\begin{tabular}{lll}
\hline & Country & Case Study Authors \& Year of Publication \\
\hline 1 & China & Dai, Chen, and Zhang (2000) \\
2 & Brazil & Krzyzanowski and Taruhn (2000) \\
3 & Italy & Giordano (2000) \\
4 & Micronesia & Cutright (2000) \\
5 & Spain & Barrionuevo (2000) \\
6 & Israel & Adler (1999) \\
7 & UK & Friend (1999) \\
8 & Australia & Costello (1999) \\
\hline
\end{tabular}

An ecological approach facilitates the delineation of stages and life cycle of purchasing nationwide library consortia better then any other approach, describing the processes of variation, selection, and retention of library consortia (Aldrich 1999). Variation in this framework is manifested through the founding of new organizations. Therefore the purchasing consortia generate not only additional goals or changes in organizational goals but new organizations or units in existing organizations (for example NESLI in the UK).

Following the existing criteria for consortia comparison, the six criteria for comparisons are: participating libraries; core program; reason for formation; funding; involvement of the larger academic libraries in the state; and governance (Potter 1997). However, another set of criteria has been examined for the purpose of the comparative analysis of nationwide purchasing library consortia. Van De Ven et al. (1975) state criteria for analysis of inter-organizational analysis are: homogeneity; domain consensus; awareness of other parties; stability; resource distribution; number of resource sources; size of network; and overlap in membership. The rationale to use Potter's criteria is to put this study in the context of the existing literature on library consortia.

\section{Findings}

Analyzing these nationwide consortia, differences and similarities can be traced. Developmental stages will be discussed, outlining the life cycle framework.

The following are the eight consortia cases compared in this study, their names, age and size:

1. Australia - CAUL CEIRC (1998). Council of Australian University Librarians Electronic Information Resources committee. Involves 39 academic libraries.

2. Brazil - ANSF (2000). Academic Network of Sao Paulo. Involves 6 academic libraries.

3. China - CALIS (1998). China Academic Library and Information System. Involves 70 academic libraries.

4. Israel - MALMAD (1997). Israel Center for Digital Information Services. Involves 8 academic libraries.

5. Italy - INFER (1999). Italian National Forum on Electronic Information Resources. Involves 15 academic and special libraries. 
6. Micronesia - FSM (1999). Federated State of Micronesia Library Service Plan 1999-2003. Involves all libraries and agencies.

7. Spain - REBIUN (1996). Committee of the Conference of Spanish University Principals. Involves all (47) academic libraries.

8. UK - JISC DNER/NESLI (1996). Joint Information System Committee, Distributed National Electronic Resources / National Electronic Site Licensing Initiative. Involves 175 academic libraries.

There are evident differences among the nationwide consortia, including size, age, and governance. Consortia size ranged from six (Brazil) to 175 (UK) and size did not correlate with consortium age. Consortium age ranged from a few months (Brazil) through several years (UK), to no age for a pre-established consortium in Italy. Governance of the purchasing consortia is diverse. For example, the consortium could be a project run by foreign agencies (Micronesia) or falling under the province of the government's ministry of education (China). A consortium could even be a unit of a national academic computer centre (Israel, U.K.) or operate under the supervision of the national library (Australia). Many of the purchasing consortia are a part of existing consortia (for example, Spain, Australia, UK). However, under the ecological framework, the variation process may create a new organization (consortium). A wide variety of organizational structures, employee rosters, and budgets are evident. Also, the number of services offered by the consortia varies, from four electronic databases in China, to 39 in Israel and 50 in the U.K. The spectrum of intra-consortium financial models includes: government budget (U.K.); membership and service fees (Australia); even a complex model combining government money, grants, parent institution budget, and membership and service fees (Israel). Despite all the above differences, which suggest a wide variety of best practices almost unique to each country, some similarities can be traced. Based on these similarities the framework for nationwide library consortia was developed.

Most of the consortia in this study are singletype consortium, consisting of academic libraries, except for the Micronesia consortium, which consists of all libraries and all agencies and museums in the Federated State of Micronesia. All eight na- tionwide consortia share similar goals, trying to improve access to electronic information, using joint licensing on a nationwide basis and enjoying the benefits of a reduced cost per unit. Some other common goals are evident, such as a shared electronic catalogue for ILL and the creation of local databases of dissertations or other domestic publications. However, probably the most remarkable similarities emerged in the founding and development process.

\section{Nationwide Consortia Life cycle}

A systematic developmental sequence emerges for the eight nationwide consortia, and the case studies cluster together in developmental stages. The findings suggest that despite the social, legal, political differences, consortium development follows a predictable life cycle. This development is sequential, its stages following each other in an algorithmic rather than causal relationship.

Several consortia belonged in the pre-established or embryonic stage, involved in efforts to reach the establishment milestone. One recently established consortium was struggling to achieve its goals and objectives in the early development stage. Some consortia were in the developmental stage, performing according to their original goals but faced with the demise of their original funding and the need to derive a new plan for viability. Finally, (alone in this analysis) in the maturation stage, one consortium was serving as its nation's major conduit for electronic resources licensing. A fifth stage of disbandment or meta-consortium was not demonstrated by the eight cases examined.

Following is classification of the consortia by stage of development at the time of the case study publication.

\begin{tabular}{|c|c|}
\hline Stage & Nationwide Consortia \\
\hline 1. Embryonic & Italy, Micronesia, Spain \\
\hline 2. Early Development & Brazil \\
\hline 3. Development & China, Israel, UK \\
\hline 4. Maturation & $\begin{array}{l}\text { Australia (Statewide Consortia - } \\
\text { U.S.) }\end{array}$ \\
\hline $\begin{array}{l}\text { 5. a. Disbanding } \\
\text { b. MetaConsortia }\end{array}$ & $\begin{array}{l}\text { Farmington Plan, CISTI (Canada), } \\
\text { ICOLC, EIFL }\end{array}$ \\
\hline
\end{tabular}

Characteristics for each stage were derived from the nationwide consortia case studies. The char- 
acteristics of earlier stages were demonstrated in the case studies of more mature consortia by case study descriptions of their histories, as well as by those that were observed at that earlier stage. For example, sources for embryonic stage characteristics were not only the case studies of Italy, Micronesia and Spain, but also those of the more developed consortia in China, Israel, and Brazil.

\section{The Embryonic Stage}

Attributes of this pre-establishment stage are based on the cases of Italy, Micronesia, and Spain (Barrionuevo 2000, Cutright 2000, Giordano 2000), as well as those of Israel, China, and Brazil (Adler 1998, Dai et al. 2000, Krzyzanowski and Taruhn 2000). Recognition of the need for collaboration is the initiating force, whether internal or external to the later established consortium. This stage is characterized by informal, voluntary networking activities and interlibrary loans, as in the cases of Italy, Israel, Spain, and Micronesia (Adler 1998, Barrionuevo 2000, Cutright 2000, Giordano 2000). Further, sporadic efforts for cooperation are evident throughout the country for single-type library consortia, as in the case of Italy and Spain (Barrionuevo 2000, Giordano 2000). These efforts provide the basis upon which a committee of academic library leaders and other stakeholders can begin to work towards establishing formal mechanisms of national cooperation. The case studies of Italy, Brazil and China exhibit this transition (Dai et al. 2000, Giordano 2000, Krzyzanowski and Taruhn 2000). Another aspect of this committee work is collection of data and best practices from other consortia worldwide. This process is illustrated in the cases of China and Italy with efforts to obtain funding and to create awareness of the need for library collaboration (Dai et al. 2000, Giordano 2000). Ultimately, it is governmental funding and approval (Adler 1998, Dai et al. 2000, Krzyzanowski and Taruhn 2000) or grants (Cutright 2000) that enables the foundation of a formal library consortium, which leads to the next developmental stage. At this point, consortia need strong internal leadership and are affected strongly by external forces in the task environment. This stage involves at least two years of intensive effort, as described in the cases of China, Israel, and Brazil (Adler 2000, Dai et al. 2000, Krzyzanowski and Taruhn 2000).

\section{Early Development}

The early developmental stage involves the transition from the embryonic to the development stage, towards an independent, self-defined and self-supported maturation stage. The cases suggest variation in the early development stage, usually mentioned as the first phase (Dai et al. 2000) or the trial period (Adler 1998). Brazil's case study provides an example of this stage (Krzyzanowski and Taruhn 2000), with information also derived from the cases of China and Israel (Adler 1998, Dai et al. 2000). At this stage, the recently established consortium is composed of a group of member libraries, using external funds to implement the plan approved at the embryonic stage (Adler 1998, Dai et al. 2000, Krzyzanowski and Taruhn 2000). The consortium at this stage defines and cultivates its processes and member relationships (Adler 1998). During the first operation period, the consortium gains understanding of the best structure, budgets, relationships, and services that fit within its specific context. The consortium also employs intensive assessment of its predecessors and works through the funding arrangements (Dai et al. 2000). It must achieve the primary goals of its charter and demonstrate benefits that will reach fruition in the development stage (Krzyzanowski and Taruhn 2000). In terms of services, the consortium at this stage might provide several shared subscriptions beyond the bibliographic network and interlibrary loan services (Adler 1998). Some of these subscriptions are international bibliographic and full text databases' subscriptions, and some are local services (Krzyzanowski and Taruhn 2000). Differentiation and integration efforts are evident at this stage, when the consortium is creating its unique identity and cultivating outside relationships. Effective boundaries management at this point is critical for consortium success. Early Development lasts for from one to three years and appears to be a prerequisite for the next developmental stage.

\section{Development}

The third developmental stage is characterized by tension between confidence and uncertainty. Success through the first developmental stages suggests sustainability, but there is uncertainty regarding the consortium's future. The consortium 
works to secure its viability by seeking funds from external sources and to suggest internal membership commitment. These funds are used to enhance operations, increase membership, and expand services. The three case studies in this stage at the time of publication emphasized these efforts. For example, the Chinese consortium devised a business economics model for their services, and the Israeli consortium planned to increase library membership (Adler 1998, Dai et al. 2000). Both described the process of extending the number and range of services. Another example of such efforts is the U.K. JISC that in 1999 approved three years funding for NESLI, which is projected by that time to be a self-financing management agent on the basis of its service revenues (Friend 1999). In this phase, the number of subscriptions shared between consortia members grows, and some services are added. The Australian consortia case study briefly described searching for the "right answer" for configuration of routines and governance structures to ensure consortium viability and stability (Costello 1999). In this stage, which lasts up to five years, efforts are focused on the consortium's effectiveness and efficiency.

\section{Maturation}

This stage was observed only in the case of the Australian consortium, which was just embarking on the maturation phase (Costello 1999). However, Potter's study of U.S. statewide consortia (1997) suggests some characteristics of mature consortia. Therefore, this stage's characteristics are based mainly on the state-wide consortia and the Australian consortium. Potter's comparative analysis included five statewide consortia (Virginia, Georgia, Texas, Louisiana, and Ohio), "newer consortia ... focused more on electronic resources" (Potter 1997, 419) - similar to the nationwide purchasing consortia. Consortium activities in this stage usually include: union catalogue/s and interlibrary loan, access to electronic resources through shared subscriptions, supporting Internet connections, and, sometimes, providing hardware for that purpose (Potter 1997). Membership is expanded and services extended beyond the publicly supported academic libraries. Although at this stage, nationwide consortia are expected to be independent from most external funding, gov- ernment or otherwise (Adler 1998, Dai et al. 2000), Potter's statewide consortia vary in their funding resources and mechanism. Some were funded as part of the state budget on an ongoing basis, and others received ad hoc funding (Potter 1997). Consortia might still get support from their parent funding agencies, at a lower proportion of support. At this stage, membership fees and service fees are a significant part of the budget (Woodsworth 1991). The size of the consortium is generally established at this stage, and most potential members are partners in the stable consortia. The consortium operates as an independent organization and is perceived as the primary conduit and negotiation agent for electronic licensing subscription (Costello 1999). At this stage, the consortium is at the performing stage and is in full operation and works to streamline its processes. Evaluation, quality assessment, and statistical measurements are employed. The consortium is stable, with a clear identity and clear boundaries. Competition from other consortia may now increase the pressure to maintain organizational boundaries and identity and to improve services by collaborating with other consortia. This stage can exist for many years, during which minor changes in membership, services, goals, and budgets may occur.

\section{Disbanding or MetaConsortia}

Though this stage was neither observed through the case studies analysis nor analyzed with the six criteria in previous literature, it seems appropriate to include it as a possible next stage. Very limited account of this stage is evident in the literature on library consortia, of consortia disbanding or of MetaConsortium (Woodsworth 1991, McFadden and Hirshon 1998, Kopp 1998). It is important to clarify that this stage will not necessarily follow the maturation stage. Disbanding or metaconsortia could follow any of the four stages of development.

Although a consortium may perform at a maturation stage for long time, it may develop further in one of two directions. The first direction is disbanding or termination of the consortia activities, which may occur at any stage of development if consortia viability weakens to that degree. However, so far this path is not common and hardly mentioned in the previous literature 
(Woodsworth 1991). Examples of consortium failure at the nationwide or statewide level are the Farmington Plan in the U.S. and, as briefly described by Woodsworth (1991), CISTI (Canada), NCLIS (U.S.), and USBE (International).

A second possible path leads to MetaConsortium, which is a consortium of consortia, founded on the basis of cooperation among several consortia to achieve shared goals. The best examples of a MetaConsortium are the International Coalition of Library Consortia (ICoLC) and the eIFL consortium. This cooperation among several consortia at the international level is now at the embryonic stage. For example, ICoLC first met at 1997, and continues to be an informal, selforganized group comprising nearly 150 library consortia from around the world. It facilitates communication and discussion among library consortia (Kopp 1998, McFadden and Hirshon 1998). As a new consortium, a MetaConsortium can be expected to follow the development stages already identified for the nationwide consortia life cycle.

To sum up, the life cycle of emerging nationwide consortia, comprised of four developmental stages, is grounded in the data of this paper's comparative analysis and supported by previous studies, specifically the comparative analysis of statewide U.S. consortia (Potter 1997). Since several stages emerged directly from the analysis and others did not, further research might be appropriate. For example, further research could document and explore the potential disbanding and MetaConsortium stages.

\section{Discussion}

Organizational growth and change can be conceived of in terms of life cycle development, which suggests that organizations are born, grow older, and die (Adizes 1979). A model of organizational development for small business growth also emphasize the emergence stages (Churchill and Lewis 1993), suggesting that entrepreneurial business follows five stages: existence, survival, success, takeoff and, finally, resource maturity. As small businesses progress, age, and grow, they require changing managerial skills.

These life cycle approaches suggest universal frameworks of developmental stages. "Scholars have argued that as firms move through various stages of growth, differing problems must be addressed, resulting in the need for different management skills, priorities, and structural configurations ..." (Hanks, Watson, Jansen and Chandler 1994, 5). A taxonomic study of life cycle models, conducted by Hank et al. (1994), outlined and characterized five common stages of development: start-up, expansion, maturity, diversification, and decline. Each stage was analyzed for: age, size, growth rate, structural form, centralization, and business tasks. These stages do not entirely fit nationwide purchasing library consortia development. However, two similar characteristics from Hank's analysis to the nationwide consortia development are: structural form and business tasks (Hank et al. 1994).

First, structural form development through the developmental stages in the business model and nationwide consortia model is similar. Nationwide library consortia evolve from very informal organizations at the embryonic stage to very welldefined ones when planning mechanism culminates and control systems are enforced at the maturation stage. However, the structural form does not change as the consortium matures. Rather, it is acted upon its specific environmental setting and the inter-organizational relationships among its participating libraries. Second, the other way in which nationwide library consortia conform to the business developmental model is in the change in focus (business task in Hank's analysis) that can be observed in the course of a consortium's progression. In early stages, the organization's focus is on identifying its niche and developing permeable boundaries through differentiation and integration, but later, focus will shift to expansion.

However, unlike the business dynamic, for nationwide consortia, size is driven by context rather than by organization age. Furthermore, the growth rate dimension of the business model does not apply to the nationwide consortia development. These differences may be due to the fact that these consortia are not-for-profit organizations. Compared to other business development models, the universal life cycle approach most closely mirrors library consortia developmental stages, but it is none-the-less a poor fit. It seems appropriate to adapt the life cycle stages to the patterns evident in the eight nationwide consortia comparative analysis. 
Life cycle models were further examined at the group level of analysis. A consortium is a group of libraries that act as an inter-organization unit, and it may follow a path of development similar to that delineated for small groups. The model conceived by Tuckman (1965) and further developed in collaboration with Jenson (Tuckman and Jensen 1971) is accepted as a normative model of group development and consists of five stages: forming, storming, norming, performing, and disbanding. This framework resembles the developmental pattern observed in the eight nationwide library consortia. However, this framework is not a good fit mainly due to the methodological concern of cross-levels of analysis.

Another frame of reference focuses on the emergence and development of networks (Ring and Van de Ven 1994, Doz, Olk and Ring 2000, Hite and Hesterly 2001). However, no attempt has been made to develop a universal developmental pattern for networks. Ring and Van de Ven (1994) proposed a dynamic process of development of cooperative inter-organizational relationships (IOR's) based on repetitive sequence of negotiation. Hite and Hesterly (2001) examined early stages of development and Doz, Olk and Ring (2000) found two distinct formation paths of R\&D consortia. All of these articles focused on the corporate rather than the public sector, and none of them schematized stages of development or considered cooperation at the national level. Furthermore, all have used pure quantitative approaches to their study, based on transaction cost theory. Finally, they assumed freedom of choice at the level of individual organizations to join, form or disband, which is not always the case in statewide library consortia.

To sum up, no framework for development at the group, organization and inter-organization level fit the findings from the comparative analysis of the eight nationwide library consortia. However, some similarities have been identified between these models and the nationwide library consortia life cycle model.

\section{Conclusions}

Nationwide purchasing consortia emerged during the last decade in many countries around the world. Despite the differences in their political, social and cultural environments, these consortia share many common characteristics and a universal developmental sequence. The main purpose of this study was to initiate a preliminary analysis of nationwide library consortia development through examination of eight examples. Under an inductive approach, a developmental model consisting of four stages emerged: embryonic, early development, development, and maturation. A potential fifth stage is disbanding or MetaConsortia at the international level.

This paper offers a frame of reference for the development of nationwide library consortia and details a universal life cycle at the inter-organizational level of analysis. This study explores a preliminary universal model for development of consortia at the inter-organizational level of analysis. Further steps are necessary to support this preliminary model, i.e. expanding data collection to include primary data, triangulating this qualitative approach with other data collection methods, and performing additional quantitative examination.

\section{References}

Adizes, I. 1979. Organizational passages - diagnosing and treating life cycle problems of organizations. Organizational Dynamics 8(1): 3-25.

Adler, E. 1998. University library cooperation in Israel: The MALMAD consortium. Information Technology and Libraries 17(1): 135-138.

Aldrich, HE. 1999. Organizations evolving. London, U.K.: Sage Publications.

Aldrich, H.E., Bolton, K.M., Baker, T., and Sasaki, T. 1998. Information exchange and governance in U.S. and Japanese R \& D Consortia: Institutional and organizational influences. IEEE Transaction on Engineering Management 45(3): 263-275.

Alexander, AW. 2000. Towards 'the perfection of work': Library consortia in the digital age. Journal of Library Administration 28(2): 1-14.

Barker, R.G. 1968. Ecological psychology: Concepts and methods for studying the environment of human behavior. Stanford, California: Stanford University Press.

Barrionuevo, MD. 2000. New strategies in library services organization: Consortia of university libraries in Spain. Information Technology and Libraries 19(2): 96-102.

Bronfenbrenner, U. 1979. The ecology of human development: Experiments by nature and design. Cambridge, Massachusetts: Harvard University Press. 
Churchill, N.C., and Lewis, V.L. 1983. The five stages of small business growth. Harvard Business Review 61(3): 30-50.

Costello, D. 1999. More, better, cheaper: The impossible dream? Information Technology and Libraries 18(3): 154-159.

Cutright, P.J. 2000. Consortia building: A handshake and smile, island style. Information Technology and Libraries 19(2): 90-95.

Dai, L., Chen, L., and Zhang, H. 2000. China academic library and information system: An academic library consortium in China. Information Technology and Libraries 19(2): 66-70.

Doz, Y.L., Olk, PM., and Ring, PS. 2000. Formation processes of R\&D consortia: Which path to take? Where does it lead? Strategic Management Journal 21(3):239-266.

Friend, J.F. 1999. New wine in a new bottle: Purchasing by library consortia in the United Kingdom. Information Technology and Libraries 18(3): 145-148.

Glaser BG., and Strauss, AL. 1967. The discovery of grounded theory. Chicago: Aldine.

Giordano, T. 2000. Digital resource sharing and library consortia in Italy. Information Technology and Libraries 19(2): 84-89.

Hanks, S.J., Watson, C.H., Jansen, E., and Chandler, G.N. 1994. Tightening the life-cycle construct: A taxonomic study of growth stage configurations in high-technology organizations. Entrepreneurship Theory and Practice 18(2): 5-29.

Hite, J.M., and Hesterly, W.S. 2001. The evolution of firm networks: From emergence to early growth of the firm. Strategic Management Journal 22(3): 275286.

\section{Editorial history:}

paper received 28 may 2002;

final version received 26 September 2002;

accepted 21 November 2002.
Kopp, J.J. 1998. Library consortia and information technology: The past, the present and the promise. Information Technology and Libraries 17(1): 7-12.

Krzyzanowski, R.F., and Taruhn, R. 2000. Electronic library for scientific journals: Consortium project in Brazil. Information Technology and Libraries 19(2): 6165.

McFadden, AB., and Hirshon, A. 1998. Hanging together to avoid hanging separately: Opportunities for academic libraries and consortia. Information Technology and Libraries 17(1): 36-44.

Potter, W.G. 1997. Recent trends in statewide academic library consortia. Library Trends 45(3): 417-434.

Ring, PS., and Van de Ven, AH. 1994. Developmental processes of cooperative interorganizational relationships. Academy of Management Review 19(1): 90-118.

Sundstrom, E., DeMuese, K.P., and Futrell D. 1990. Work teams: Applications and effectiveness. The American Psychologist 45(2): 120-133.

Tuckman, BW. 1965. Developmental sequences in small groups. Psychological Bulletin 63: 384-399.

Tuckman, B.W., and Jensen, M.A.C. 1977. Stages of small group development revisited. Group and Organization Studies 2(4): 419-427.

Van De Ven, Andrew H., Emmett, Dennis C., and Koenig, Richard Jr. 1975. Framework for interorganizational analysis, in: Negandhi, Anant R. (Ed.), Interorganization theory. Kent, Ohio: Kent State University Press. 19-38.

Wicker, AW. 1979. An introduction to ecological psychology. Belmont, CA: Wadsworth, Inc.

Woodsworth, A. 1991. Library cooperation and networks. N.Y.: Neal-Schuman Publishers. 